\title{
A case report of rhabdomyolysis and osteofascial compartment syndrome in a patient with hypothyroidism and diabetes
}

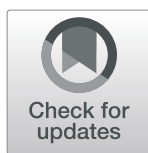

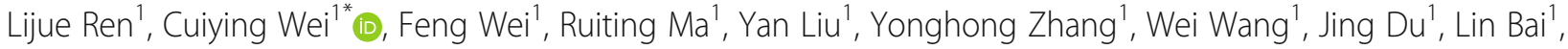
Yexia Xue and Shaohua Cui $^{2}$

\begin{abstract}
Background: Hypothyroidism is frequent and has various forms of muscle involvement. We report the diagnosis and treatment of a case of rhabdomyolysis, bilateral osteofascial compartment syndrome (OCS) of the lower extremities, and peroneal nerve injury causing bilateral foot drop in a diabetic patient with hypothyroidism.

Case presentation: A 66-year-old man with diabetes for 22 years was admitted because of drowsiness, tiredness, facial swelling, and limb twitching for 2 months, and red and swollen lower limb skin for 3 days. Serum creatinine kinase (CK), CK-MB, myoglobin (Mb), blood glucose, and HbA1c were elevated. TSH, thyroid peroxidase antibodies, and antithyroglobulin antibodies were elevated. FT3 and FT4 were low. Urine was dark brown. He was diagnosed with hypothyroidism, rhabdomyolysis, and OCS. CK, CK-MB, and Mb returned to normal after treatment with thyroid hormone, insulin, albumin infusion, ceftriaxone, ulinastatin, and hemofiltration, and the redness and swelling of the lower limbs were relieved, but the patient developed dropping feet. The patient recovered well but had to undergo rehabilitation.

Conclusion: Hypothyroidism may induce rhabdomyolysis, OCS, and other complications. This case reminds us of the importance of screening for hypothyroidism and strengthens the clinicians' understanding of the disease.
\end{abstract}

Keywords: Hypothyroidism, Rhabdomyolysis, Osteofascial compartment syndrome, Foot drop, Case report

\section{Background}

Hypothyroidism is a frequent occurrence in the endocrinology department, with a prevalence of $1-2 \%$ in iodine-sufficient countries but can reach $5.3 \%$ in some European countries [1]. The common clinical manifestations are systemic metabolic reduction syndromes such as cold sensitivity, fatigue, memory loss, and edema [2, 3]. About $79 \%$ of adult patients with hypothyroidism have various forms of muscle involvement such as myalgia, muscle cramps, and muscle stiffness [4].

\footnotetext{
* Correspondence: weicuiying9@163.com

1Department of Endocrinology, First Affiliated Hospital of Baotou Medical College, Inner Mongolia University of Science and Technology, 41 Linyin Road, Kun District, Baotou City 014010, Inner Mongolia, China

Full list of author information is available at the end of the article
}

Rhabdomyolysis (RM) and osteofascial compartment syndrome (OCS) [5, 6] are rare manifestations of hypothyroidism. RM can cause acute kidney injury (AKI), electrolyte disturbance, metabolic acidosis, and OCS in the presence of limb compression, leading to morbidity and even mortality. Hypothyroidism, combined with the above complications, is extremely dangerous and needs timely treatment [2, 3, 7-9].

We report the diagnosis and treatment of a case of RM, bilateral lower extremity OCS, and peroneal nerve injury causing bilateral foot drop in a diabetic patient with hypothyroidism.

(C) The Author(s). 2021 Open Access This article is licensed under a Creative Commons Attribution 4.0 International License, which permits use, sharing, adaptation, distribution and reproduction in any medium or format, as long as you give appropriate credit to the original author(s) and the source, provide a link to the Creative Commons licence, and indicate if changes were made. The images or other third party material in this article are included in the article's Creative Commons licence, unless indicated otherwise in a credit line to the material. If material is not included in the article's Creative Commons licence and your intended use is not permitted by statutory regulation or exceeds the permitted use, you will need to obtain permission directly from the copyright holder. To view a copy of this licence, visit http://creativecommons.org/licenses/by/4.0/. The Creative Commons Public Domain Dedication waiver (http://creativecommons.org/publicdomain/zero/1.0/) applies to the data made available in this article, unless otherwise stated in a credit line to the data. 


\section{Case presentation}

A 66-year-old retired man (Han Chinese) was referred to the endocrinology unit of the First Affiliated Hospital of Baotou Medical College, Inner Mongolia University of Science and Technology, due to poor plasma glucose control and severely painful lower limbs on April 21, 2020. He reported sleepiness, fatigue, swelling of the face, and occasional lower limb convulsions for the past 2 months. He complained of pain, redness, and swelling in the lower limbs for 3 days and gradually worsening symptoms, which severely affected his daily activities and sleep quality. The patient had a history of type 2 diabetes for 22 years. Due to the poor effect of metformin, he had been injecting mixed recombinant human insulin (30/ 70) $44 \mathrm{U} /$ day for the past 5 years. His fasting blood glucose fluctuated around $9.0 \mathrm{mmol} / \mathrm{L}$. The patient reported no history of trauma, excessive exercise, fever, drinking alcohol, and medication (other than insulin) in the past 6 months. The patient reported no family genetic history. Physical examination on admission showed stable vitals, with a heart rate of $72 \mathrm{bpm}$ and blood pressure of $130 / 70 \mathrm{mmHg}$, but dry and pale skin and slow speech. The whole body was swollen, especially the lower limbs, and the anterior shin of both legs were red and swollen. Local skin tension was high, and tenderness was obvious.

The blood investigations revealed serum creatine kinase (CK) at 9774 U/L (reference: $50-310 \mathrm{U} / \mathrm{L}$ ), CK isoenzyme (CK-MB) at $115.2 \mathrm{U} / \mathrm{L}$ (reference: 0-24 U/L), cardiac troponinI (cTnI) at $0 \mathrm{U} / \mathrm{L}$, myoglobin $(\mathrm{Mb})$ at $>$ $3811 \mu \mathrm{g} / \mathrm{L}$ (reference: $0-70 \mu \mathrm{g} / \mathrm{L}$ ), albumin (Alb) at 48.8 $\mathrm{g} / \mathrm{L}$ (reference: $40-55 \mathrm{~g} / \mathrm{L}$ ), alanine aminotransferase (ALT) at $46 \mathrm{U} / \mathrm{L}$ (reference: 9-50 U/L), aspartate aminotransferase (AST) at $139 \mathrm{U} / \mathrm{L}$ (reference: $15-40 \mathrm{U} / \mathrm{L}$ ), lactate dehydrogenase (LDH) at $579 \mathrm{U} / \mathrm{L}$ (reference: 120 $250 \mathrm{U} / \mathrm{L})$, and $\alpha$-hydroxybutyrate dehydrogenase $(\mathrm{HBDH})$ at $419 \mathrm{U} / \mathrm{L}$ (reference:72-182 U/L), suggesting RM. Blood glucose was $13.7 \mathrm{mmol} / \mathrm{L}$ (reference: 3.9-7.7 $\mathrm{mmol} / \mathrm{L}$ ), HbA1c was $10.6 \%$ (reference: $3.9-6.2 \%$ ), hemoglobin was $159 \mathrm{~g} / \mathrm{L}$ (reference: $130-175 \mathrm{~g} / \mathrm{L}$ ), white cell counts was $11.98 \times 10^{9} / \mathrm{L}$ (reference: $3.5-9.5 \times 10^{9}$ / $\mathrm{L}$ ), and platelet count was in the normal range (125$350 \times 10^{9} / \mathrm{L}$ ). Free triiodothyronine (FT3) was $0.06 \mathrm{pg} / \mathrm{ml}$ (reference: $2.3-4.2 \mathrm{pmol} / \mathrm{L}$ ), free thyroxine (FT4) was $2.78 \mathrm{pmol} / \mathrm{L}$ (reference: $7.5-17.4 \mathrm{pmol} / \mathrm{L}$ ), and TSH was $145.6 \mathrm{mIU} / \mathrm{L}$ (reference: $0.35-5.5 \mathrm{mIU} / \mathrm{L}$ ). Subsequent tests were suggestive of Hashimoto's thyroiditis, with raised thyroid peroxidase antibodies at $661.8 \mathrm{IU} / \mathrm{ml}$ (reference: $0-34 \mathrm{IU} / \mathrm{ml}$ ) and positive antithyroglobulin antibody at $366.20 \mathrm{KIU} / \mathrm{L}$ (reference:0-115 KIU/L). Blood electrolytes, renal function, coagulation function, brain natriuretic peptide, chest radiograph, and abdominal ultrasound were normal. There were no erythrocytes on microscopic examination, although his urine was bloody in appearance. Ultrasound of both lower extremities suggested uneven thickening of the arteries and media of the lower extremities with plaques and no abnormalities in the veins of both lower extremities. Swelling of the lower limbs caused by vascular occlusion and thrombosis was excluded. There was no ST-T segment change on the ECG.

Considering RM, fluid replacement, maintenance of water and electrolyte balance, diuresis, alkalized urine, penicillin, insulin, thyroid hormone replacement, and loxoprofen for pain relief were given immediately. The lower extremity swelling continued to progress, with high tension and thin skin. Tension blisters appeared on the right ankle on April 22, and muscle enzymes increased progressively, urine was dark brown, urine output was $3500 \mathrm{ml} /$ day. On April 23, creatinine did not elevate $[116 \mu \mathrm{mol} / \mathrm{L}$ (reference: $57-111$ )], but CK rose at 48,118 U/L (reference: 50-310 U/L). Mb was $>3811 \mu \mathrm{g} /$ L, ALT was $196 \mathrm{U} / \mathrm{L}$, AST was $1027 \mathrm{U} / \mathrm{L}, \mathrm{LDH}$ was 1422 $\mathrm{U} / \mathrm{L}$, and $\mathrm{HBDH}$ was $798 \mathrm{U} / \mathrm{L}$. An orthopedist was consulted and suggested lower limb OCS. Surgery could not be considered due to the high risk of open decompression and complications such as poorly healing incision because of poor blood glucose control and hypothyroidism.

Hemofiltration was started on the evening of April 23. The lower limb pain and redness gradually reduced, and the levels of CK, CK-MB, Mb, ALT, AST, LDH, and HBDH gradually decreased. CK fell to $8301 \mathrm{U} / \mathrm{L}$ (reference: $50-310 \mathrm{U} / \mathrm{L}$ ) and $\mathrm{Mb}$ to $1183 \mu \mathrm{g} / \mathrm{L}$ on April 28. Blood Alb and hemoglobin gradually decreased, and APTT and PT were prolonged. On April 29, there were large ecchymoses on the right waist and right thigh, and the anterior tibial swelling of the two lower legs was aggravated again. Ultrasound showed intermuscular hematoma of both lower legs and subcutaneous hematoma of the right thigh. The feet were drooping and could not stretch back. The worsening of the disease was considered related to abnormal blood coagulation caused by RM.

Considering the necrosis of the soft tissue of the anterior tibia, ceftriaxone ( $2 \mathrm{~g} / \mathrm{qd})$ was given from April 29 to May 7. On April 30, the levels of CK again increased to 14,292 U/L. Blood filtration, fluid replacement, gradually increasing the dose of thyroid hormone $(75 \mu \mathrm{g} / \mathrm{d})$ and insulin (insulin pump therapy, basic dose $30 \mathrm{U}$, high dose $10 \mathrm{U}$ before meals), infusion of albumin ( $20 \mathrm{~g} /$ day, continued for 1 week), and other treatments (glutathione $1.8 \mathrm{~g} /$ day and esomeprazole $40 \mathrm{mg} / 12 \mathrm{~h}$ ) were continued. The condition of the patient gradually stabilized. On May 6, hemofiltration was stopped due to the improvement of the redness and swelling of the lower limbs, and APTT was normal. Since the levels of CK $(4650 \mathrm{U} / \mathrm{L})$ 
and $\mathrm{Mb}(232.0 \mu \mathrm{g} / \mathrm{L})$ were still higher than the normal range, treatment was continued. Afterward, the lower limbs were slightly red but without pain and swelling. Muscle enzymes continued to decline, with CK from $4650 \mathrm{U} / \mathrm{L}$ to $1547 \mathrm{U} / \mathrm{L}$ and $\mathrm{Mb}$ to normal. FT3/FT4 gradually rose. Fasting blood glucose fluctuated around $7.0 \mathrm{mmol} / \mathrm{L}$, and postprandial blood glucose fluctuated around $10.0 \mathrm{mmol} / \mathrm{L}$. The foot drop did not recover (Fig. 1).

The patient was discharged on May 19. The lower limbs were slightly red but without pain and discomfort. $\mathrm{CK}$ was $1547 \mathrm{U} / \mathrm{L}$, and $\mathrm{Mb}$ was normal. CK was checked every 10 days and FT3/FT4 every month after that. Rehabilitation was recommended. On May 30, the patient was able to stand, but walking was slightly unstable. CK was $818 \mathrm{U} / \mathrm{L}$, and $\mathrm{Mb}$ was normal. On July 12 , the patient's feet were still drooping; there was no redness or swelling in the lower limbs and occasional swelling of the ankles. The levels of TSH, FT3, FT4, and CK were normal. The patient is undergoing rehabilitation. The patient's treatment process is shown in Fig. 1. The changes in related laboratory indicators are shown in Supplementary Tables S1, S2, and S3.

\section{Discussion and conclusions}

The causes of RM are diverse and can be generally divided into physical factors such as crushing, trauma, strenuous exercise, electric shock, and high fever, and non-medical factors such as drugs, poisons, infections, electrolyte disturbances, autoimmune diseases, and endocrine and genetic metabolic diseases [10]. In patients with hypothyroidism, CK can be slightly to moderately elevated [5]. Still, RM caused by hypothyroidism is relatively rare $[5,6]$, and the reported cases are mostly due to the use of lipid-lowering drugs such as statins or vigorous exercise [11, 12]. Salehi et al. [6] summarized 10 previously reported cases of RM caused by hypothyroidism in adults. One case was a patient with subclinical hyperthyroidism who was taking propylthiouracil. There were four patients with a known diagnosis of HS. In five patients, thyroid disease was not previously diagnosed. There were six cases without any risk factors for rhabdomyolysis.

The patient reported here had severe hypothyroidism, prominent symptoms of myalgia and fatigue, dark urine, serum CK up to $48,118 \mathrm{U} / \mathrm{L}$, and $\mathrm{Mb}>3811 \mu \mathrm{g} / \mathrm{L}$, leading to a definite diagnosis of RM. The patient had no history of taking medication in the past 6 months, and there were no other known causes of RM, such as poison, exercise, and infection. Therefore, RM in this patient was considered to be caused by hypothyroidism. Furthermore, his antibodies to TPOAb and TgAb were increased significantly, indicating Hashimoto's

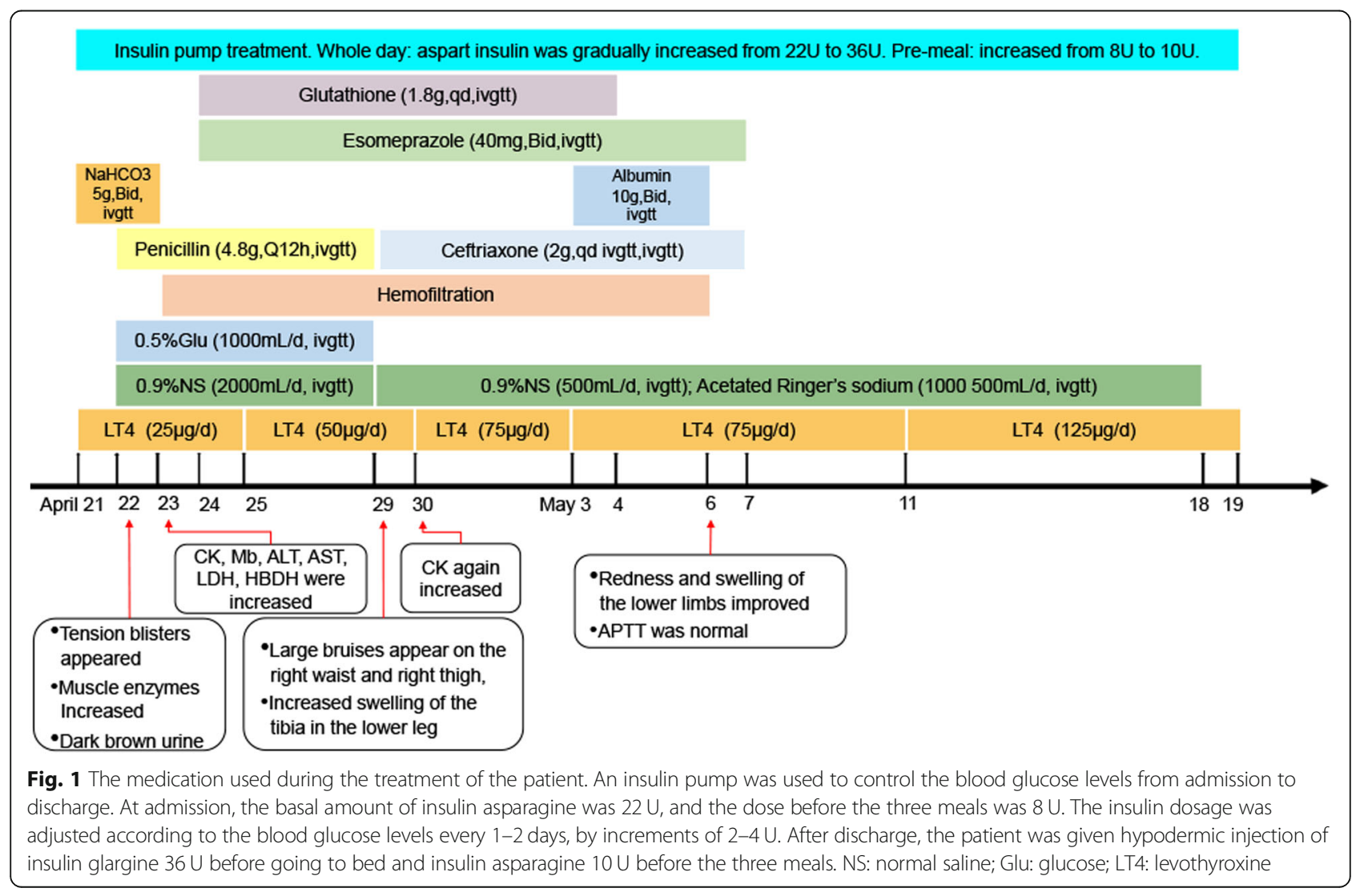


thyroiditis, which has also been reported as a possible cause of RM [13]. In addition, the incidence of adult RM in the diabetic state is about $10 \%$, and the reported cases were all caused by acute complications such as diabetic ketoacidosis and diabetic hyperosmolar state [14, 15]. Severe dehydration, insufficient oxygen supply to the local tissues, and exhausted sodium and potassium pumps on the muscle cell membrane will lead to muscle cell lysis. At the same time, severe hyperglycemia activates aldose reductase in skeletal muscle cells, leading to the accumulation of large amounts of sorbitol and fructose, causing osmotic cell swelling and damaging skeletal muscle cells. Acute and chronic hyperglycemia can also produce various inflammatory factors that directly damage local muscle tissue $[16,17]$. In the case reported here, the patient's blood glucose levels were increased without predisposing factors such as hypernatremia, hypokalemia, and hyperosmolar state. Blood glucose at admission was $13.5 \mathrm{mmol} / \mathrm{L}$. After insulin injection, the fast blood glucose was around $7 \mathrm{mmol} / \mathrm{L}$, and postprandial blood glucose was around $10 \mathrm{mmol} / \mathrm{L}$. Therefore, blood sugar might be involved in the occurrence of RM, but it is not the main cause.

The mechanism by which hypothyroidism causes RM is unclear. It is well known that the active form of thyroid hormone is triiodothyronine (T3), which plays a central role in muscle function and integrity. The main fuel substrate for muscle energy metabolism is glycogen. T3 can stimulate the metabolism of carbohydrates and increase the mobilization and utilization of glycogen in muscle tissue. Muscle contraction and relaxation mainly depend on the energy produced by adenosine triphosphate (ATP) hydrolysis and mitochondrial oxidative respiratory chain. T3 can regulate the above link $[18,19]$. T3 also affects myosin thick filaments and muscles. Therefore, the currently accepted hypothesis of hypothyroidism leading to RM is that hypothyroidism inhibits glycogen breakdown and damages mitochondrial activity, causing a series of metabolic dysfunctions [2022]. Hypothyroidism can convert muscle fibers from fast convulsions type II to slow convulsions type I so that actin-myosin has poor contractility, myosin ATPase activity is low, and ATP conversion rate in skeletal muscle is low, resulting in insufficient muscle blood vessel perfusion, hypoxia of muscle tissue, and low muscle energy storage [23].

OCS can be caused by reducing the size of the compartment or increasing its contents. OCS is usually unilateral and is found bilaterally in only $<10 \%$ of the cases [24]. Because the calf compartment is small and tight, any swelling inside it can easily cause OCS. OCS, as a complication of RM secondary to hypothyroidism, is a rare condition. In 1993, Thacker et al. [25] reported OCS with hypothyroidism for the first time. In 2015,
Chaudhary et al. [26] mentioned that there were only five previous cases. In hypothyroidism, due to the proliferation of connective tissue in mucinous edema, the size of the bone fascia compartment might be reduced, and, at the same time, the increase in the content of the anterior tibia area might be due to interstitial edema, muscle necrosis, and swelling caused by glycosaminoglycan deposition [25, 27]. Increased capillary permeability, slow lymphatic drainage, and extravasation of interstitial protein-rich liquid can also participate in OCS [28]. The development of OCS in the calf can cause the compression of the common peroneal nerve and cause dropping of the feet or the deposition of glycosaminoglycans in the nerve sheath of the deep peroneal nerve might also cause the same effect [29].

The differences in the treatment of hypothyroidism might be related to the patient's age, comorbidities, and the severity of muscle damage. Chaudhary et al. [26] described a case of hypothyroidism-caused rhabdomyolysis and acute OCS resulting in acute episodes of prolapsed feet. Although normal thyroid function was achieved in the case presented here, muscle weakness symptoms did not improve. The treatment of RM and OCS includes a combination of multiple measures. The treatment principle of RM is to remove the cause as soon as possible and give a large amount of fluid and alkaline urine treatment as early as possible to prevent and treat critical complications such as acute kidney injury (AKI). Continuous renal replacement therapy (CRRT) is an important and very effective treatment. If blood creatinine rises to three times the baseline value or reaches $353.6 \mu \mathrm{mol} / \mathrm{L}$, urine volume is less than $0.3 \mathrm{~mL} / \mathrm{kg} / \mathrm{h}$, or the patient is $12 \mathrm{~h}$ without urine, blood purification treatment should be started [30]. We believe that AKI has not occurred in this patient, and the electrolyte and creatinine were normal throughout the treatment process. The main reason is that CRRT was started within a short time after admission. Then, blood myoglobin, CK, and CK-MB decreased significantly, indicating that CRRT could effectively remove blood creatinine, myoglobin, interferon- $\alpha$, interleukin (IL)- 1 , IL-2, and other substances, and preventing AKI, disseminated intravascular coagulation, and multiple organ dysfunction [31].

For OCS, especially traumatic OCS, surgical incision decompression can achieve good results. Nevertheless, it has been reported that the surgical decompression gains in hypothyroidism-related OCS are not large, and conservative treatment has similar results [32]. Since the patient reported here had a high surgical risk due to hyperglycemia and mucinous edema of hypothyroidism, surgery was not performed.

Clinicians should be aware that hypothyroidism can cause RM and OCS and can happen without 
predisposing factors. Therefore, it is important to check thyroid function in patients with RM. For patients with hypothyroidism combined with RM, early implementation of CRRT can effectively prevent AKI and multiple organ dysfunction. In addition, patients with increased muscle pain, obvious limb swelling, and increased muscle enzymes need to be screened for during treatment. This case reminds us of the importance of screening for hypothyroidism and strengthens the clinicians' understanding of the disease.

\section{Abbreviations}

RM: Rhabdomyolysis; OCS: Osteofascial compartment syndrome; AKI: Acute kidney injury; CK: Creatine kinase; CK-MB: creatine kinase isoenzyme; cTnl: cardiac troponinl; Mb: Myoglobin; Alb: Albumin; ALT: Alanine aminotransferase; AST: Aspartate aminotransferase; LDH: Lactate dehydrogenase; HBDH: a-hydroxybutyrate dehydrogenase; FT3: Free triiodothyronine; FT4: Free thyroxine; ATP: Adenosine triphosphate

\section{Supplementary Information}

The online version contains supplementary material available at https://doi. org/10.1186/s12902-021-00868-6.

Additional file 1: Supplementary Table S1. Key biochemical values of patients during hospitalization and out-of-hospital. Supplementary

Table S2. Thyroid function of patients during hospitalization and out-ofhospital. Supplementary Table S3. Coagulation function of patients during hospitalization.

\section{Acknowledgments}

We thank Dr. WanYi Shi and Dr. LiXia Geng for help in the diagnosis and treatment of our patient. We thank the patient for allowing us to publish the case report and to use the images taken.

\section{Authors' contributions}

Conceptualization: CYW; Data curation: RTM, YL, YHZ, SHC Investigation: WW, JD, LB, YXX; Resources: LJR; Supervision: CYW, FW; Writing- original draft: LJR, CYW; Writing -review \& editing: All authors. All authors read and approved the final manuscript.

\section{Funding}

This work was supported by a grant (\#81660020) (CY. Wei) from the National Natural Science Foundation of China. The funding bodies played no role in the design of the study and collection, analysis, and interpretation of data and in writing the manuscript.

\section{Availability of data and materials}

The datasets used and/or analyzed during the current study are available from the corresponding author on reasonable request.

\section{Declarations}

\section{Ethics approval and consent to participate}

Written informed consent was obtained prior to the study.

\section{Consent for publication}

Written informed consent was obtained from the patient for publication of this Case report and any accompanying images. A copy of the written consent is available for review by the Editor of this journal.

\section{Competing interests}

The authors declare that they have no competing interests.

\section{Author details}

${ }^{1}$ Department of Endocrinology, First Affiliated Hospital of Baotou Medical College, Inner Mongolia University of Science and Technology, 41 Linyin
Road, Kun District, Baotou City 014010, Inner Mongolia, China. ${ }^{2}$ Intensive Care Unit, First Affiliated Hospital of Baotou Medical College, Inner Mongolia University of Science and Technology, Baotou 014010, Inner Mongolia, China.

Received: 22 March 2021 Accepted: 8 October 2021

Published online: 24 October 2021

\section{References}

1. Taylor PN, Albrecht D, Scholz A, Gutierrez-Buey G, Lazarus JH, Dayan CM, et al. Global epidemiology of hyperthyroidism and hypothyroidism. Nat Rev Endocrinol. 2018;14:301-16.

2. Chaker L, Bianco AC, Jonklaas J, Peeters RP. Hypothyroidism. Lancet. 2017; 390:1550-62.

3. Garber JR, Cobin RH, Gharib H, Hennessey JV, Klein I, Mechanick Jl, et al. Clinical practice guidelines for hypothyroidism in adults: cosponsored by the American Association of Clinical Endocrinologists and the American Thyroid Association. Thyroid. 2012;22:1200-35.

4. Shan Z, Chen L, Lian X, Liu C, Shi B, Shi L, et al. lodine status and prevalence of thyroid disorders after introduction of mandatory universal salt iodization for 16 years in China: a cross-sectional study in 10 cities. Thyroid. 2016;26: 1125-30.

5. Sindoni A, Rodolico C, Pappalardo MA, Portaro S, Benvenga S. Hypothyroid myopathy: a peculiar clinical presentation of thyroid failure. Review of the literature. Rev Endocr Metab Disord. 2016:17:499-519.

6. Salehi N, Agoston E, Munir I, Thompson GJ. Rhabdomyolysis in a patient with severe hypothyroidism. Am J Case Rep. 2017:18:912-8.

7. Tiong M, Wilson S, Walker R. Hypothyroidism and renal impairment: an easily missed diagnosis. Intern Med J. 2019;49:276-8.

8. Jonklaas J, Bianco AC, Bauer AJ, Burman KD, Cappola AR, Celi FS, et al. Guidelines for the treatment of hypothyroidism: prepared by the american thyroid association task force on thyroid hormone replacement. Thyroid. 2014;24:1670-751

9. Alexander EK, Pearce EN, Brent GA, Brown RS, Chen H, Dosiou C, et al. 2017 guidelines of the American Thyroid Association for the diagnosis and Management of Thyroid Disease during Pregnancy and the postpartum. Thyroid. 2017;27:315-89.

10. Paternoster M, Capasso E, Di Lorenzo P, Mansueto G. Fatal exertional rhabdomyolysis. Literature review and our experience in forensic thanatology. Leg Med. 2018;35:12-7.

11. Ambapkar SN, Shetty N, Dwivedy A, Malve HO. Statin-induced rhabdomyolysis in patient with renal failure and underlying undiagnosed hypothyroidism. Indian J Crit Care Med. 2016;20:305-7.

12. Naz A, Issa M. Rhabdomyolysis and acute renal impairment in a patient with hypothyroidism: a case report. Case Rep Med. 2014;2014:139170.

13. Nikolaidou C, Gouridou E, llonidis G, Boudouris G. Acute renal dysfunction in a patient presenting with rhabdomyolysis due to hypothyroidism attributed to Hashimoto's disease. Hippokratia. 2010;14:281-3.

14. Frank M, Finsterer J. Creatine kinase elevation, lactacidemia, and metabolic myopathy in adult patients with diabetes mellitus. Endocr Pract. 2012;18: 387-93.

15. Bialo SR, Agrawal S, Boney CM, Quintos JB. Rare complications of pediatric diabetic ketoacidosis. World J Diabetes. 2015;6:167-74.

16. Mercer $\mathrm{S}$, Hanks L, Ashraf A. Rhabdomyolysis in pediatric patients with diabetic Ketoacidosis or Hyperglycemic Hyperosmolar state: a case series. Glob Pediatr Health. 2016:3:2333794×16671391.

17. Li W, Gong C, Wu D, Liu M. Two case reports of severe pediatric hyperosmolar hyperglycemia and diabetic ketoacidosis accompanied with rhabdomyolysis and acute renal failure. J Pediatr Endocrinol Metab. 2014;27: 1227-31.

18. Hurwitz $L$, McCormick D, Allen IV. Reduced muscle alpha-glucosidase (acidmaltase) activity in hypothyroid myopathy. Lancet. 1970;1:67-9.

19. McDaniel HG, Pittman CS, Oh SJ, DiMauro S. Carbohydrate metabolism in hypothyroid myopathy. Metabolism. 1977;26:867-73.

20. Altay M, Duranay M, Ceri M. Rhabdomyolysis due to hypothyroidism. Nephrol Dial Transplant. 2005;20:847-8.

21. Al-Ismaili Z, Piccioni M, Zappitelli M. Rhabdomyolysis: pathogenesis of renal injury and management. Pediatr Nephrol. 2011;26:1781-8.

22. Crunkhorn S, Patti ME. Links between thyroid hormone action, oxidative metabolism, and diabetes risk? Thyroid. 2008;18:227-37.

23. Kuo HT, Jeng CY. Overt hypothyroidism with rhabdomyolysis and myopathy: a case report. Chin Med J. 2010;123:633-7. 
24. Mubarak SJ, Hargens AR. Acute compartment syndromes. Surg Clin North Am. 1983;63:539-65.

25. Thacker AK, Agrawal D, Sarkari NB. Bilateral anterior tibial compartment syndrome in association with hypothyroidism. Postgrad Med J. 1993;69:8813.

26. Chaudhary N, Duggal AK, Makhija P, Puri V, Khwaja GA. Statin-induced bilateral foot drop in a case of hypothyroidism. Ann Indian Acad Neurol. 2015;18:331-4.

27. Hsu SI, Thadhani RI, Daniels GH. Acute compartment syndrome in a hypothyroid patient. Thyroid. 1995;5:305-8.

28. Parving HH, Hansen JM, Nielsen SL, Rossing N, Munck O, Lassen NA. Mechanisms of edema formation in myxedema--increased protein extravasation and relatively slow lymphatic drainage. N Engl J Med. 1979; 301:460-5.

29. Bland JH, Frymoyer JW. Rheumatic syndromes of myxedema. N Engl J Med. 1970;282:1171-4.

30. Petejova N, Martinek A. Acute kidney injury due to rhabdomyolysis and renal replacement therapy: a critical review. Crit Care. 2014;18:224.

31. Tandukar S, Palevsky PM. Continuous renal replacement therapy: who, when, why, and how. Chest. 2019;155:626-38.

32. Muir P, Choe MS, Croxson MS. Rapid development of anterotibial compartment syndrome and rhabdomyolysis in a patient with primary hypothyroidism and adrenal insufficiency. Thyroid. 2012;22:651-3.

\section{Publisher's Note}

Springer Nature remains neutral with regard to jurisdictional claims in published maps and institutional affiliations.

- fast, convenient online submission

- thorough peer review by experienced researchers in your field

- rapid publication on acceptance

- support for research data, including large and complex data types

- gold Open Access which fosters wider collaboration and increased citations

- maximum visibility for your research: over $100 \mathrm{M}$ website views per year

At BMC, research is always in progress.

Learn more biomedcentral.com/submissions 